\title{
ADVANTAGES OF LAPAROSCOPIC MANAGEMENT OF HYDATID CYST OF THE LIVER: A CASE REPORT
}

\author{
Ignatov V., K. Ivanov, I. Minev, N. Kolev, D. Hristov, A. Tonev, R. Madjov* \\ Department of General and Operative Surgery, *Department of Surgery, \\ University Hospital "St. Marina", Medical University - Varna \\ Reviewed by: Assoc. Prof. G. Kirov, MD, PhD
}

\begin{abstract}
Hydatid cyst is a parasitosis caused by Taenia Echinococcus. In the last 10 years, new methods of treatment of the hydatid cyst have been proposed (percutaneous or laparoscopic). Laparoscopic surgery may be used for treating a variety of benign hepatic lesions in selected patients. The anatomic location of the lesions are more important than any other peculiarity when laparoscopic management is used. The aim of this report is to discuss the effects and feasibility of laparoscopic treatment of hydatid cyst of liver. The procedure is feasible and safe, shortens the postoperative hospitalization period, reduces the number of complications as well as the overall costs and facilitates a rapid social reintegration. All these arguments recommend the laparoscopic approach as a standard procedure for hepatic hydatid disease.
\end{abstract}

Keywords: Laparoscopy, Cyst Hydatid, Liver

\section{INTRODUCTION}

Hydatid cyst disease is a parasitosis caused by Taenia Echinococcus. Human disease is a, dead end" which interrupts the biological cycle of the parasite. Hepatic localization is the most frequent $(60 \%)$, because the infestation occurs by digestive way, and liver is the first filter on this way. The disease is endemic in the Balkan Area and in Eastern Europe. Man is an accidental host for the parasite; the dog is the final host and the cow, the sheep and the pig are intermediary hosts. Except for the most frequent localizations (hepatic $-60 \%$ and pulmonary $-30 \%$ ), brain, spleen, bones, kidney, mesocolon, ovary and pelvic are known as potential sites.

Treatment is surgical, when it does not respond to drug administration.(1) Therapy consists of inactivation of the cyst with scolicide (hypertonic saline), removal of the cyst contents without contaminating the patient, followed by appropriate management of any remaining cavity. $(1,2)$ The cyst is approached laparoscopically by using the same hydatid aseptic techniques as in open surgery.(3) The procedure is contraindicated in patients with secondarily infected cysts, or suspected biliary communication - when the aspirate is bile-stained, because of the increased risk of complications.(2) In these cases, open surgery is preferred.

Address for correspondence:

V. Ignatov, Dept of General and Operative Surgery, University Hospital "St. Marina", 1st Nr. Smirnensky blvd, Varna-9010, BULGARIA

\section{CASE REPORT}

We represent a 59-year-old, female with a 7-month history of recurrent right-upper-quadrant pain. She had not had icter ever. She had computed tomography demonstrated solitary hydatid cyst in the right lobe of the liver. (fig. 1.)

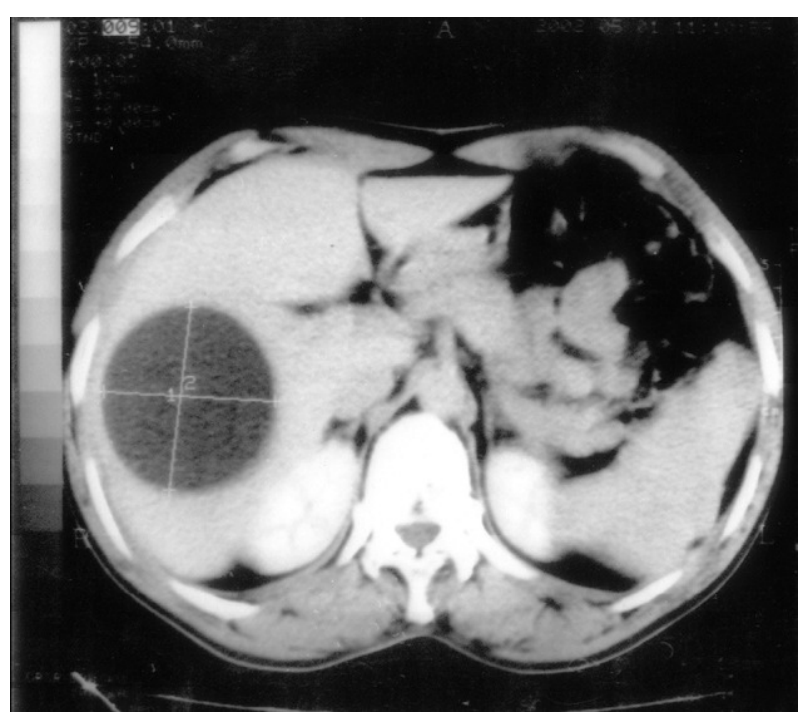

Figure 1. Abdominal computed tomography scan showing a 7.41-cm cyst in the right liver.

After the diagnosis, medical treatment with albendazole $400 \mathrm{mg}$ per day was initiated 4 weeks before surgery. We suggested a laparoscopic surgical approach for manage- 
ment of the cyst. Preoperative liver function tests were normal.

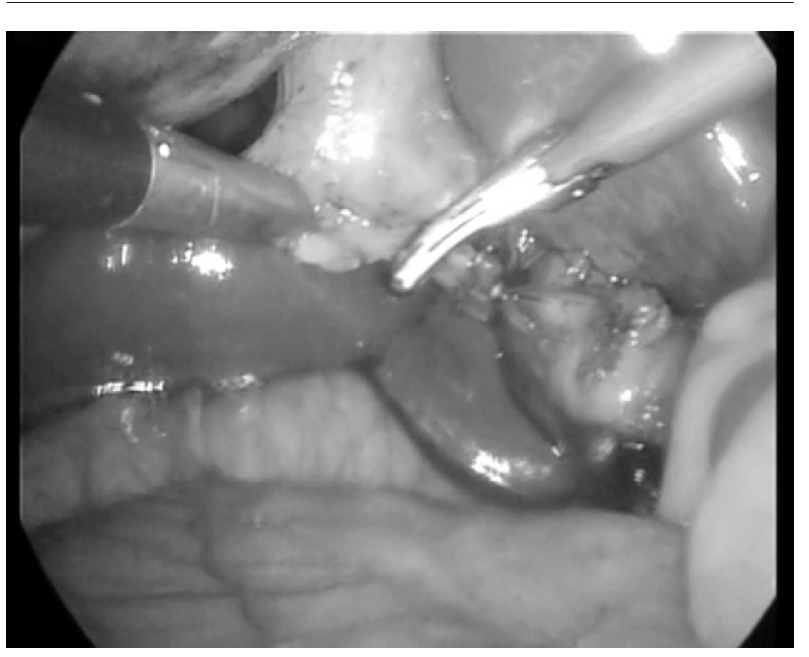

Fig. 2 Ligation of the cystic duct

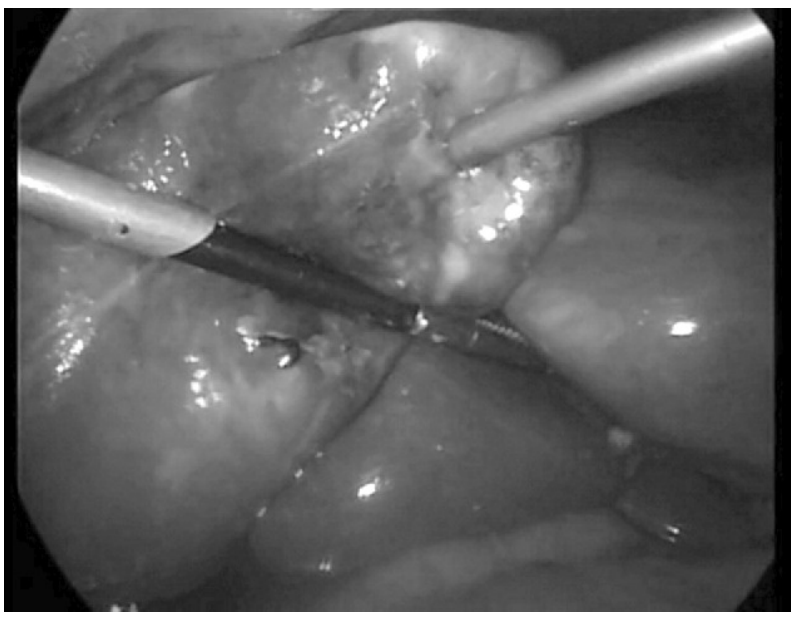

Fig. 3 Hypertonic saline insuflation

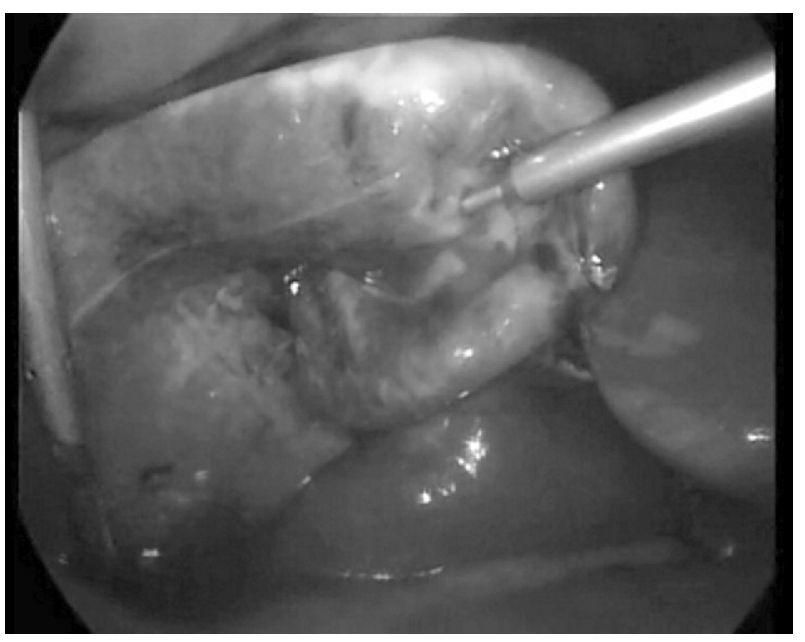

Fig. 4 Hypertonic saline aspiration

In this case we used two 10-mm and two 5-mm trocars. The hydatid cyst was approached laparoscopically by using the same hydatid asepsis techniques as in open surgery. Diag- nostic laparoscopy was performed to visualize the cyst. First we performed laparoscopic cholecystectomy. (Fig. 2)

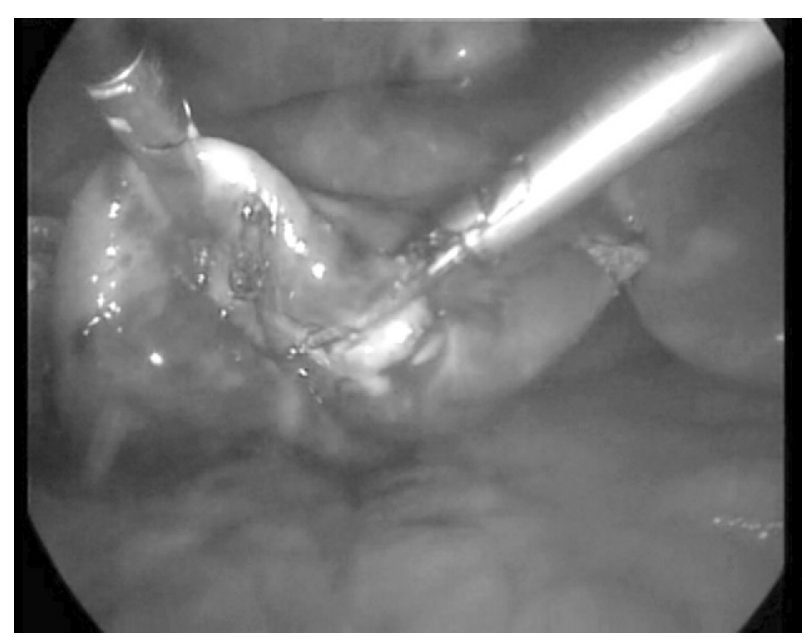

Fig. 5 Excision part of the wall

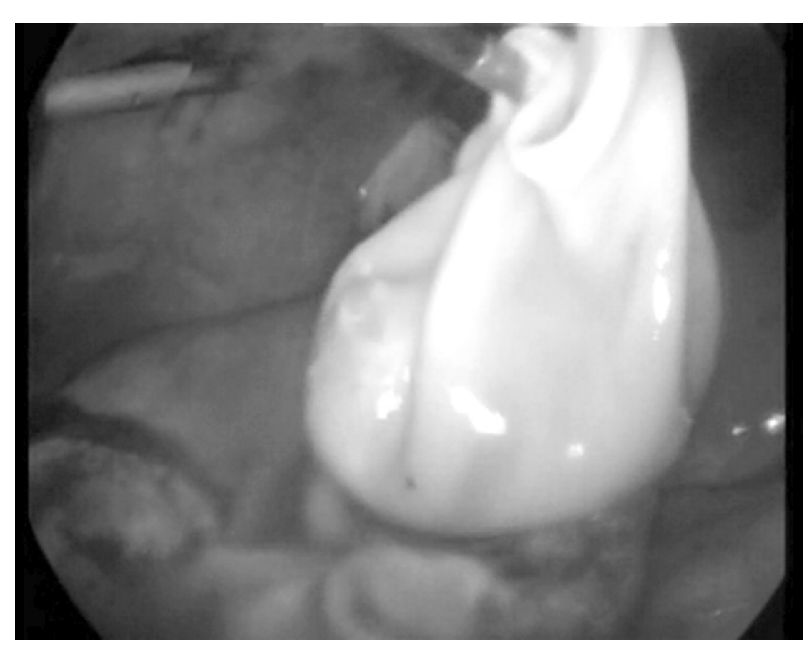

Fig. 6 Extraction of the cyst

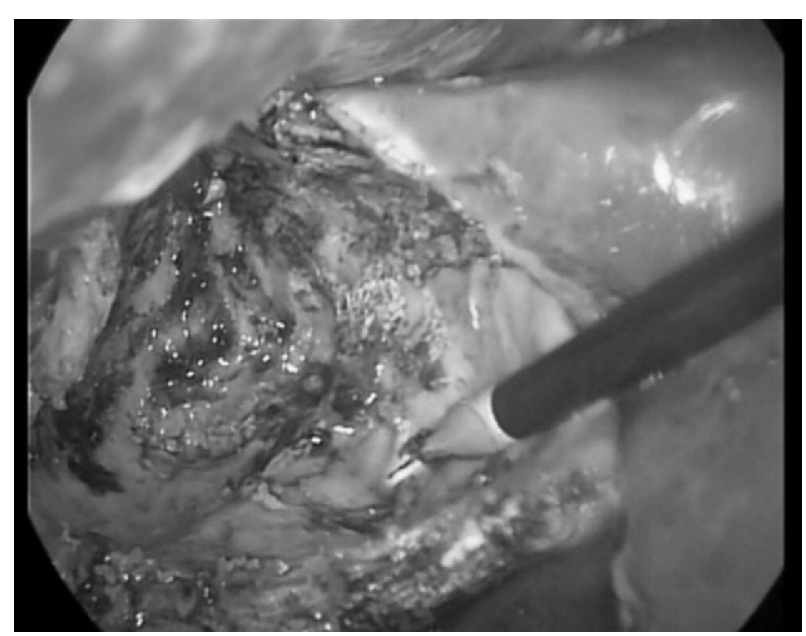

Fig. 7 Elecrtocoagulation of the cavity

A Veress needle was introduced and hypertonic saline $(30 \% \mathrm{NaCl})$ was injected to surround the cyst. Afterwards, we punctured the cyst, and hypertonic saline $(30 \% \mathrm{NaCI})$ was injected into it. The saline solution was allowed to re- 
main for 5 minutes and changed 4 to 5 times. (Fig. 3 and 4) A portion of the cyst wall was excised for pathological examination. (Fig. 5) The germinative layer was removed with care and placed in extraction bag. (Fig. 6) The pericystic cavity was lavaged with Braunol solution and electrocoagulated. (Fig. 7) At the end we placed a drain in the pericystic cavity. (Fig. 8)

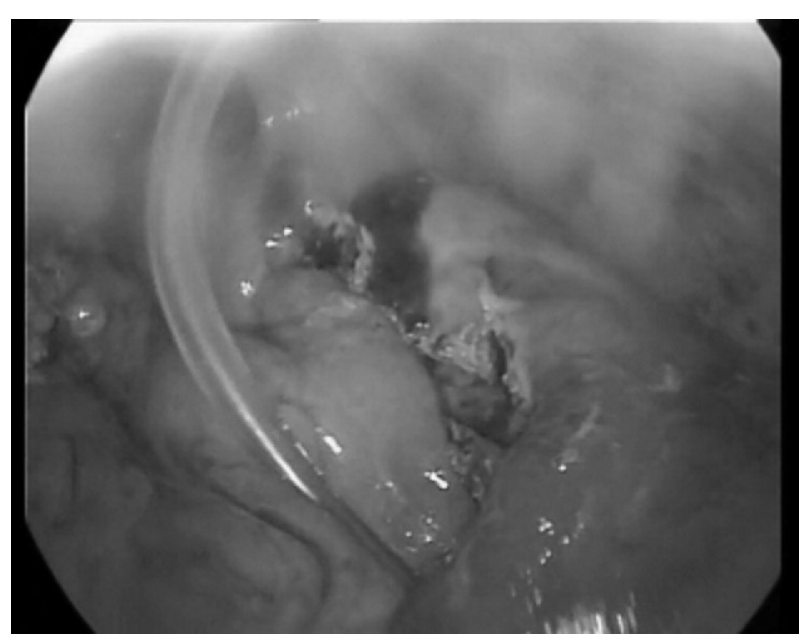

Fig. 8 Drainage

The patient did well postoperatively and was discharged on the eight postoperative day. There were no complications in the postoperative period.

\section{DISCUSSION}

Minimally invasive techniques (percutaneous or laparoscopic) have well known advantages that have increased their practice. Their use in the treatment of hepatic hydatid cysts started about 12 years ago, when Khoury et al (1991) and Acunas (1992) performed percutaneous drainage, and Saglam (1992) performed laparoscopic drainage of hepatic hydatid cyst. These minimally invasive methods were and still are of little use in the treatment of hepatic hydatid cysts. We found some studies similar to our series, which presented the laparoscopic treatment of hepatic hydatid cysts and recommended the use of minimally invasive techniques under the cover of modern scolicidal drugs. $(5,6,7)$ An experimental percutaneous technique was first described in 1985 and was performed on the human body for the first time after 6 years. Bastid et al reported 14 cases of hepatic hydatid cysts with diameters between 42 and 180 $\mathrm{mm}$ that were treated by this method. This treatment is good for the young hepatic hydatid cysts with thin walls (hydatid cyst type I, II or III after Gharbi classification). The inactivation was done with hypertonic saline $30 \%$. In the absence of billiary fistula, the residual cavity was treated with alcohol mixed with lipiodol. There was no anaphylactic shock, no complication or relapse during the first 18 months. The hospitalization period in this group was $24-72$ hours (practically no hospitalization). $(3,4,8)$

\section{CONCLUSION}

The open surgical approach of hepatic hydatid cysts is highly expensive due to the postoperative period, therefore a laparoscopic approach may be advocated. The minimally invasive method shortens the postoperative hospitalization period, reduces the number of complications as well as the overall costs and facilitates a rapid social reintegration. All these arguments recommend the laparoscopic approach as a standard procedure for hepatic hydatid disease.

\section{REFERENCES:}

1. Schwartz SI. Liver. In: Schwartz SI, ed. Principles of Surgery. Seventh ed. New York: McGraw-Hill International Inc; 1999; 1395-1435.

2. Barnes SA, Lillemoe KD. Liver abscess and hydatid cyst disease. In: Zinner MJ, ed. Abdominal Operations. Tenth ed. London: Prentice Hall International Inc; 1997;1513-1545.

3. Khoury G, Geagea T, Hajj A, Jabbour-Khoury S, Baraka A, Nabbout G. Laparoscopic treatment of hydatid cysts of the liver. Surg Endosc. 1994;8(9):1103-1104.

4. Bickel A, Loberant N, Shtamler B. Laparoscopic treatment of a liver hydatid cyst. Br J Surg. 1994;81(4):627.

3. Burlui D, Rosca M. The surgery of hepatic hydatid cyst. Ed Med Bucuresti 1977.

4. Ghelase F, Georgescu I, Nemee R. Chirurgie generala. Ed Did Pedag Bucuresti, 1999, 291- 308.

5. Proca E, Coman C, Coman B. Tratat de patologie chirurgicalr. Patologie chirurgical $\Gamma$ toracic $г$. Ed Med Bucuresti 1991, 191- 233.

6. Marks J, Mouiel J, Katkhouda N, Gugenheim J, Fabiani P. Laparoscopic liver surgery. A report on 28 patients. Surg Endosc 1998; 12: 331-334.

7. Verma GR, Bose SM. Laparoscopic treatment of hepatic hydatid cyst. Surg Laparosc Endosc 1998; 8: 280-282.

8. Gil-Grande LA, Boixeda D, Ledo L. Tratamiento actual de la hydatidosis humana. Enferm Infect Microbiol Clin 1987; 5: 627-632. 